\title{
EXFOLIATIVE CYTOLOGICAL FINDINGS IN ORAL POTENTIALLY MALIGNANT DISORDERS
}

\author{
Mehwish Waris ${ }^{1}$, Sajjad Ahmad ${ }^{2}$, Muhammad Mumtaz Khan², Sabeen Nasir', Qurat-Ul-Ain Mushtaq ${ }^{3}$, Farooq Taj ${ }^{4}$ \\ ${ }^{1}$ Department of Oral Pathology, KMU-Institute of Dental Sciences, Kohat - Pakistan \\ 2Department of Pathology, Peshawar Medical College, Peshawar - Pakistan \\ ${ }^{3}$ Department of Pathology, KMU-Institute of Dental Sciences, Kohat - Pakistan \\ ${ }^{4}$ Department of Prosthodontics, KMU-Institute of Dental Sciences, Kohat - Pakistan
}

\begin{abstract}
Objective: Patients with oral potentially malignant disorders (OPMDs) are at risk for development of malignancy. This study was designed to assess the dysplastic changes in oral exfoliative cytological specimens from OPMD cases thus screening patients who may need biopsy for evaluation and progression of their lesion.
\end{abstract}

Materials and Methods: This descriptive cross-sectional study was conducted at Histopathology Laboratory of Peshawar Medical College, Peshawar for which samples were collected from two dental hospitals and private dental clinics of Peshawar. The study included 20 cases of clinically diagnosed Oral Potentially Malignant Disorders (OPMDs); including 10 cases of leukoplakia and 10 cases of oral lichen planus (OLP), and 20 age and gender matched healthy controls, after observing a strict inclusion and exclusion criteria. A pre-designed proforma was used to collect the data, which was later analyzed in SPSS version 21.

Results: A total of 40 participants had a mean age of $48.25 \pm 10.01$ years with gender distribution of $32(80 \%)$ males and $8(20 \%)$ females, giving a male to female ratio of $4: 1$. The duration of OPMD lesions had a mean of $2.3 \pm 4.4$ years. On Oral Exfoliative Cytology (OEC), 10\% OPMDs showed atypical changes and $90 \%$ showed no such changes, as compared to healthy controls which exhibited a normal cytology without any atypia. As per Oral Bethesda Criteria, 18 (90\%) OPMD cases were Negative for Intraepithelial Lesion/Malignancy (NILM) and 2 (10\%) showed Low grade Squamous Intraepithelial Lesions (LSIL). Buccal mucosa $12(60 \%)$ was the most common site of lesions.

Conclusion: This study concluded that dysplastic cytological findings were seen only in $10 \%$ of OPMD cases thus saving majority of the patients from the need to go through the invasive biopsy procedure.

Keywords: Oral Potentially Malignant Disorders; Cytology; Oral Exfoliative Cytology

This article may be cited as: Waris M, Ahmad S, Khan M, Nasir S, Mushtaq Q, Taj F. Exfoliative cytological findings in oral potentially malignant disorders. J Med Sci 2021 January;29(1):2-5

\section{INTRODUCTION}

OPMDs are defined by WHO as "the risk of malignancy being present in a lesion or condition either during the time of initial diagnosis or at a future date"1. The cardinal OPMDs include: leukoplakia, erythroplakia, oral lichen planus (OLP) and oral submucous fibrosis (OSF) ${ }^{1}$. There are some conditions which can potentiate OPMDs leading to their transformation to frank malignancy. These include: actinic cheilitis, some inherited disorders, like xeroderma pigmentosum and Fanconi's anemia, immunodeficiency disorders and prolonged treatment with immunosuppressive drugs ${ }^{2}$. The worldwide prevalence of OPMDs in gen-

Correspondence

Dr. Mehwish Waris

Department of Oral Pathology, KMU-Institute of Dental

Sciences, Kohat - Pakistan.

Email: mahwashwaris@gmail.com

Cell: +92-332-9239610

Date received: 27-08-2020

Date revised: $\quad 07-02-2021$

Date accepted: $18-02-2021$ eral population is about $1-5 \%^{3}$. Average age of patients with OPMDs is $50-69$ years, however some recent studies reveal occurrence of OPMDs in about $5 \%$ cases under 30 years of $a^{2} e^{4}$. In frequency order the OPMDs are usually found on the buccal mucosa, gingivae, tongue and floor of the mouth ${ }^{4}$. The incidence and prevalence of OPMDs in Pakistani population have not been reported in the recent literature, however a Karachi based study published in 1976 reported a prevalence rate of $705 / 100,000$ of population $^{5}$. Dysplasia of oral mucosa is characterized by cellular atypia, loss of normal maturation and stratification ${ }^{6}$. The deviation of one or more architectural or cellular features from the normal appearing cell or group of cells is referred to as 'atypia'? Diagnostic procedures used for OPMDs include histopathological methods like scalpel and punch biopsy; cytopathological methods including exfoliative cytology and oral brush biopsy; and molecular methods like immunohistochemistry ${ }^{8}$. There is a rapid turnover of cells in the oral cavity, and the exfoliated cells play an important role in the diagnosis of OPMDs. Oral Exfoliative Cytology (OEC) examines the exfoliated cells obtained from an oral 
epithelial surface, under a microscope. It is a non-invasive, simple and sensitive staining technique used as an adjunct for biopsy ${ }^{9}$. Based on The Bethesda System (TBS) different researchers have developed their own systems for diagnosis of oral cytology. The Japanese Society of Clinical Cytology (JSCC) developed "Oral Bethesda System" (OBS) in 2013, which when tested showed a sensitivity of $94 \%$ and a false negative rate of $6 \%^{10}$. The OBS has four categories; Negative for Intraepithelial Lesion or Malignancy (NILM), Low grade Squamous Intraepithelial Lesion (LSIL) that shows mild keratinized low grade atypical cells, High grade Squamous Intraepithelial Lesion (HSIL) that shows moderate keratinized moderate atypical grade cells, and Squamous Cell Carcinoma (SCC) that shows abundantly keratinized severely dysplastic cells ${ }^{11}$. The objective of this study is to compare exfoliative cytological changes in clinically diagnosed OPMDs with healthy controls having no oral lesions, so as to use the findings of OEC to screen OPMDs for biopsy.

\section{MATERIAL \& METHODS}

This descriptive cross-sectional study was conducted at Histopathology Laboratory of Peshawar Medical College, Peshawar and samples were collected from Peshawar Dental College, Khyber College of Dentistry, and some private dental clinics of Peshawar. This study included 20 clinically diagnosed OPMD patients (10 each of leukoplakia and OLP) and 20 age and gender matched individuals as healthy controls free of any oral lesions. Cytology smears of OPMD cases were collected from site of the lesion. OEC samples of healthy controls were obtained from the buccal mucosa. A disposable medium quality toothbrush was used for each subject. Firstly, the subjects rinsed their oral cavity with water, then the brush was applied repeatedly in one direction over the entire lesion using moderate pressure, until pinpoint bleeding was observed. Smears were made on clean dried glass slides and placed immediately for fixation in 95\% ethyl alcohol for 30 minutes. The slides were stained with hematoxylin and eosin (H\&E). The slides having at least 30 well preserved cells from intermediate or parabasal layers were considered adequate for analysis ${ }^{12}$. All the data from each subject was recorded on a pre-designed proforma, which was later analyzed in SPSS v21.0.

\section{RESULTS}

This study included 40 individuals (20 cases and 20 controls), with a mean age of $48.25 \pm 10.01$ years with gender distribution of $32(80 \%)$ males and $8(20 \%)$ females, with a male to female ratio of $4: 1$ in both the groups (Table 1). The duration of OPMD lesions had a mean of $2.3 \pm 4.4$ years. Among OPMD cases, 10 (50\%) were having Leukoplakia, while $10(50 \%)$ were of OLP. In cases, as per Oral Bethesda Criteria, 18 (90\%) were Negative for Intraepithelial Lesion/Malignancy (NILM), while 2(10\%) had Low grade Squamous Intraepithelial Lesion (LSIL) (Table 2). Buccal mucosa $12(60 \%)$ was the most common site of lesions in OPMDs, followed by vestibule 5(25\%) and alveolar mucosa with $3(15 \%)$. The comparison of oral exfoliative cytological changes in cases and controls are shown in table 3.

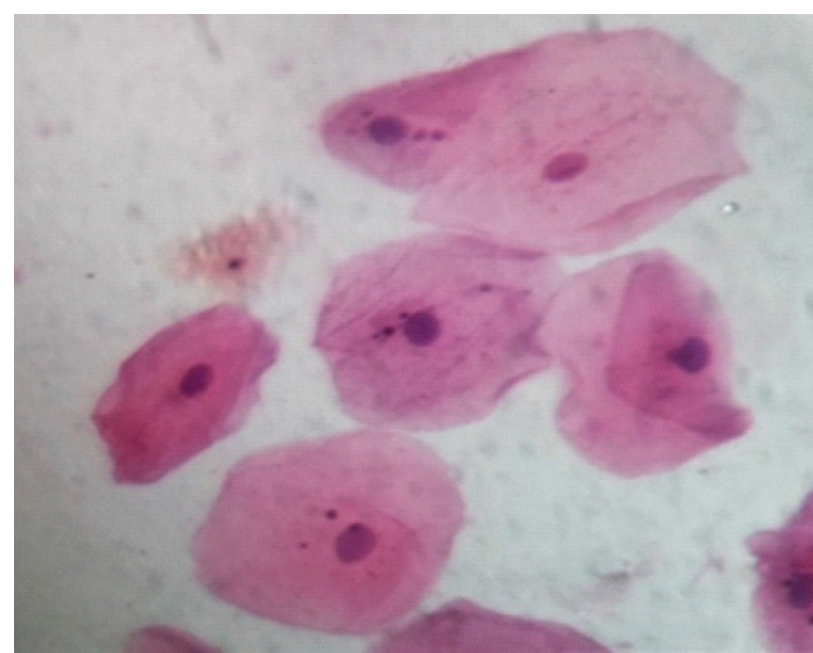

Fig 1:A group of normal oral squamous epithelial cells (H\&E; 40x)

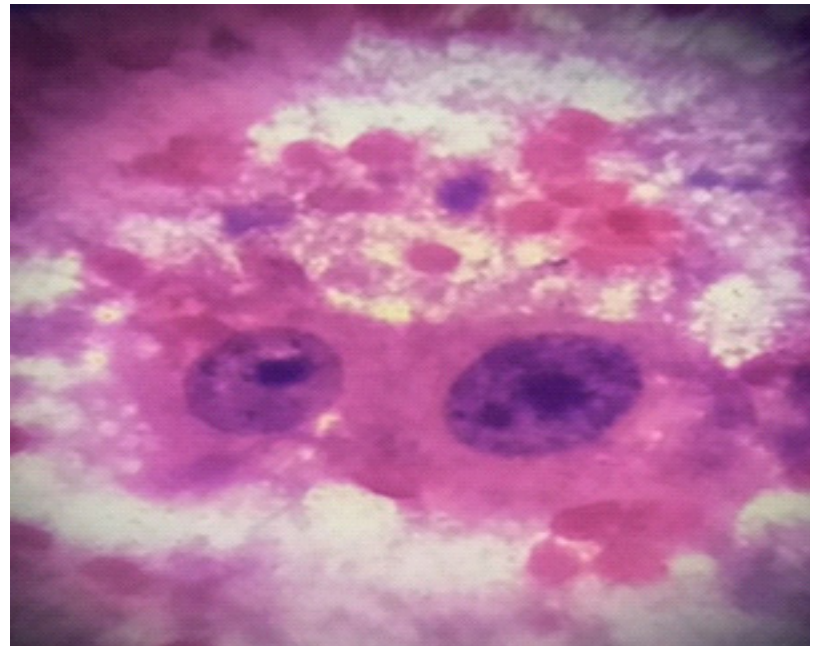

Fig 2: Dysplastic oral squamous epithelial cells with prominent nucleoli, vesicular chromatin and altered N/C ratio (H\&E; 40x)

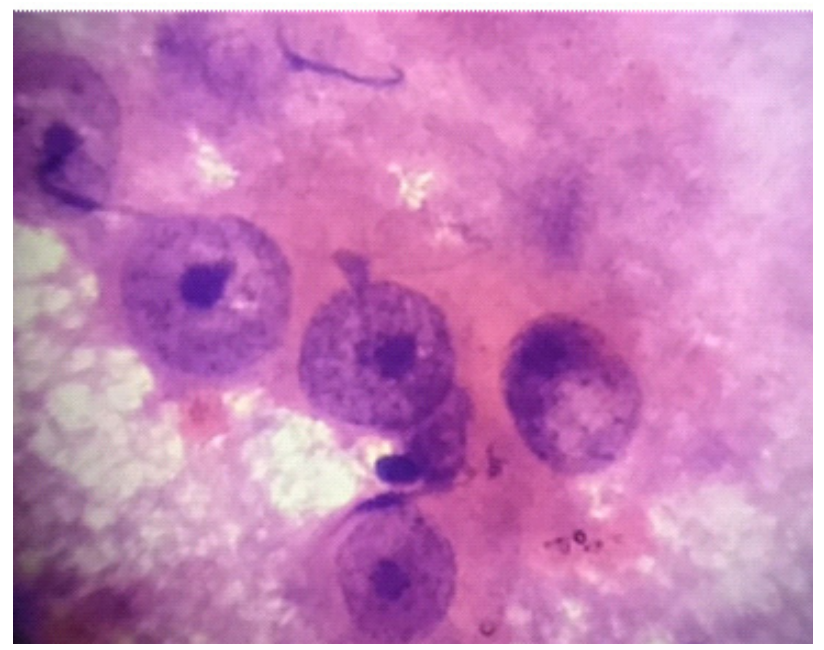

Fig 3: A group of dysplastic oral squamous epithelial cells with prominent nucleoli, vesicular chromatin and altered $\mathrm{N} / \mathrm{C}$ ratio (H\&E; 40x) 
Exfoliative Cytological Findings In Oral Potentially Malignant Disorders.

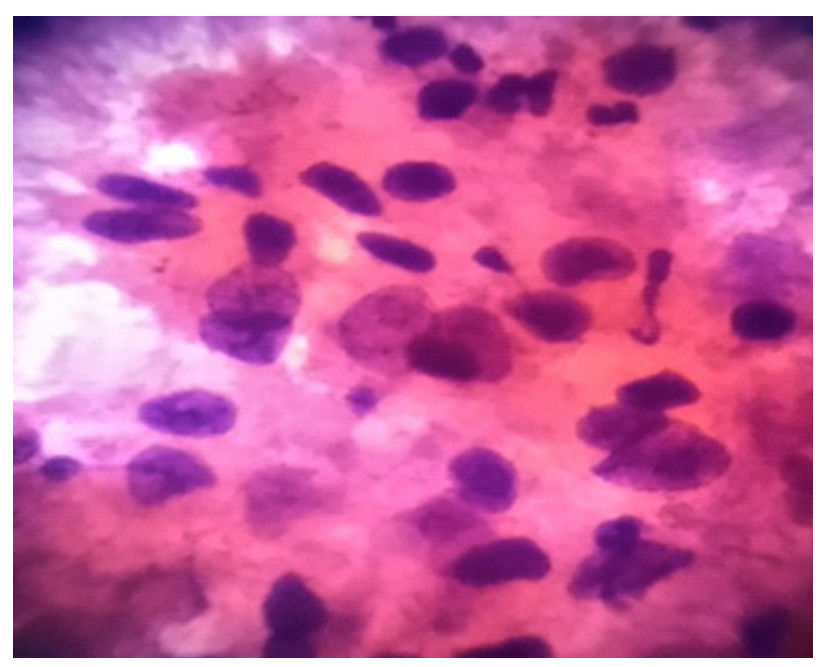

Fig 4: A cluster of oral squamous epithelial cells with severe dysplasia showing prominent cellular and nuclear pleomorphism (H\&E; 40x)

Table 1: Age and gender matched OPMDs cases and controls

\begin{tabular}{|c|c|c|}
\hline & Cases & Controls \\
\hline Age range & $30-70$ years & $30-70$ years \\
\hline Mean age & $48.25 \pm 10.01$ years & $48.25 \pm 10.01$ years \\
\hline M:F ratio & $4: 1$ & $4: 1$ \\
\hline
\end{tabular}

Table 2: Classification of OPMD cases based on Oral Bethesda Criteria

\begin{tabular}{|c|c|}
\hline Oral Bethesda Criteria & Number (\%) \\
\hline $\begin{array}{c}\text { Negative for Intraepithelial Lesion / Malignan- } \\
\text { cy (NILM) }\end{array}$ & $18(90)$ \\
\hline $\begin{array}{c}\text { Low grade Squamous Intraepithelial Lesion } \\
\text { (LSIL) }\end{array}$ & $2(10)$ \\
\hline Total & $20(100)$ \\
\hline
\end{tabular}

\section{DISCUSSION}

Patients with OPMDs are at increased risk of developing carcinomas, therefore early diagnosis and management is important.

In this study the dysplastic features in OPMDs included cellular and nuclear pleomorphism, hyperchromatism, chromatin clumping, prominent nucleoli, multinucleation, nuclear membrane irregularities, nuclear enlargement and increased nucleus to cytoplasm ratio. Similar changes were studied by Kabiraj et al, in their study on OEC in leukoplakia and OLP, in which $90 \%$ (36 out of 40 ) of leukoplakia cases and 65\% (26 out of 40 ) of OLP cases showed minor atypia. The atypical cytological changes observed in their study included cellular and nuclear pleomorphism and hyperchromatism ${ }^{9}$. Histopathology of most white oral lesions show hyperkeratosis, as was observed by Abidullah et al in their study on white, non-scrapable oral mucosal lesions. Their studied showed that $90 \%$ (59/66) leukoplakia cases and 100\% (30/30) OLP cases showed hyperkeratosis.(13) Similar findings on OEC were observed in this study, where $90 \%(18 / 20)$ of the OPMD
Table 3: Cytological changes in OPMD cases and controls

\begin{tabular}{|c|c|c|c|c|}
\hline \multicolumn{3}{|c|}{ Cytological Changes } & $\begin{array}{c}\text { Cases } \\
\mathrm{n}(\%)\end{array}$ & $\begin{array}{c}\text { Controls } \\
\mathrm{n}(\%)\end{array}$ \\
\hline & \multirow{2}{*}{\multicolumn{2}{|c|}{ Hypercellular }} & & \\
\hline Cellularity & & & $14(70 \%)$ & $15(75 \%)$ \\
\hline & \multicolumn{2}{|c|}{ Hypocellular } & $6(30 \%)$ & $5(25 \%)$ \\
\hline \multirow[t]{2}{*}{ Cell type } & \multicolumn{2}{|c|}{ Superficial } & $18(90 \%)$ & $20(100 \%)$ \\
\hline & \multicolumn{2}{|c|}{ Intermediate } & $20(100 \%)$ & 20 (100\%) \\
\hline \multirow[t]{2}{*}{ N/C Ratio } & \multicolumn{2}{|c|}{ Normal } & $18(90 \%)$ & 20 (100\%) \\
\hline & \multicolumn{2}{|c|}{ Increased } & $2(10 \%)$ & 0 \\
\hline \multirow{2}{*}{$\begin{array}{l}\text { Cellular } \\
\text { Pleomor- } \\
\text { phism }\end{array}$} & \multicolumn{2}{|c|}{ Present } & $2(10 \%)$ & 0 \\
\hline & \multicolumn{2}{|c|}{ Absent } & $18(90 \%)$ & $20(100 \%)$ \\
\hline \multirow{2}{*}{$\begin{array}{c}\text { Individual } \\
\text { cell kerati- } \\
\text { nization }\end{array}$} & \multicolumn{2}{|c|}{ No Change } & $2(10 \%)$ & $18(90 \%)$ \\
\hline & \multicolumn{2}{|c|}{ Hyperkeratinization } & 18 (90\%) & $2(10 \%)$ \\
\hline \multirow{14}{*}{$\begin{array}{l}\text { Nuclear } \\
\text { changes }\end{array}$} & \multirow{2}{*}{$\begin{array}{l}\text { Nuclear En- } \\
\text { largement }\end{array}$} & Present & $2(10 \%)$ & 0 \\
\hline & & Absent & $18(90 \%)$ & $20(100 \%)$ \\
\hline & \multirow{2}{*}{$\begin{array}{l}\text { Irregular } \\
\text { Nuclear } \\
\text { Membrane }\end{array}$} & Present & $2(10 \%)$ & 0 \\
\hline & & Absent & $18(90 \%)$ & 20 (100\%) \\
\hline & \multirow{2}{*}{$\begin{array}{l}\text { Multinucle- } \\
\text { ation }\end{array}$} & Present & $1(5 \%)$ & 0 \\
\hline & & Absent & 19 (95\%) & 20 (100\%) \\
\hline & \multirow{2}{*}{$\begin{array}{l}\text { Prominent } \\
\text { Nucleoli }\end{array}$} & Present & $1(5 \%)$ & 0 \\
\hline & & Absent & 19 (95\%) & $20(100 \%)$ \\
\hline & \multirow{2}{*}{$\begin{array}{l}\text { Chromatin } \\
\text { Clumping }\end{array}$} & Present & $1(5 \%)$ & 0 \\
\hline & & Absent & 19 (95\%) & $20(100 \%)$ \\
\hline & \multirow{2}{*}{$\begin{array}{l}\text { Hyperchro- } \\
\text { matism }\end{array}$} & Present & $1(5 \%)$ & 0 \\
\hline & & Absent & $19(95 \%)$ & $20(100 \%)$ \\
\hline & \multirow{2}{*}{$\begin{array}{l}\text { Nuclear } \\
\text { Pleomor- } \\
\text { phism }\end{array}$} & Present & $2(10 \%)$ & 0 \\
\hline & & Absent & $18(90 \%)$ & $20(100 \%)$ \\
\hline
\end{tabular}

cases (leukoplakia and OLP) showed hyperkeratinization.

Trakroo et al (2015), in their study on efficacy of oral brush biopsy in oral premalignant and malignant lesions observed that only $36.36 \%$ (12/33) cases of OPMDs (leukoplakia \& OLP) showed atypical changes, while $63.64 \%$ (21/33) OPMDs showed normal cells with no signs of atypia ${ }^{14}$. The results of their study are comparable with those of this study as majority of the OPMDs i.e. $90 \%(18 / 20)$ showed no signs of atypia and only $2 \%$ $(2 / 20)$ showed atypical changes on OEC. The same study by Trakroo et al reported a male predominance (86\%) in OPMDs and malignant lesions as is found in our study (80\%). The most common site of OPMD lesions in their study was the buccal mucosa $(69.7 \%)$ which is similar to this study $(60 \%)^{14}$. A study conducted on exfoliative cytology as a tool for monitoring oral pre-malignant and malignant lesions by Segura et al (2015) showed that only $7 \%$ of leukoplakia and OLP cases exhibited normal cytology with no atypical changes and $93 \%$ exhibited cellular atypia, which is at odds with this study ${ }^{15}$. Duration of the lesion is a vital parameter in determination of its advancement 
to malignancy. Long duration of OPMD lesions is a risk factor for their malignant transformation ${ }^{16}$. In our study we had a mean duration of $2.3 \pm 4.4$ years for OPMD cases but those with dysplastic changes persisted for a longer time than the rest i.e. $2.99 \pm 0.41$ years. Patients with clinically suspicious lesions detected on oral examination are candidates for OEC. The lesions with features of dysplasia on cytological examination need confirmation by histopathology for a definitive diagnosis and management. Not all suspicious oral lesions have to undergo biopsy. If dysplasia is not seen on OEC examination then they can be kept under surveillance. Chances of compliance with screening by OEC are higher as this is a non-invasive and affordable method ${ }^{17}$. Dysplastic cytological features on the other hand identify the patients who need confirmation with biopsy of the lesion to rule out malignancy. In this study, only 2 OPMD cases out of 20 showed dysplasia on OEC and therefore, it can be used to screen OPMD cases for biopsy.

\section{CONCLUSION}

This study concluded that all OPMDs patients should be screened by OEC examination because atypical changes are seen in some of the clinically diagnosed OPMD cases. The risk for progression to malignancy in such cases should be assessed through biopsy of the lesion.

\section{REFERENCES}

1. Swathi S, Manyam R. Non-invasive techniques for detection of oral potentially malignant disorders (OPMDs)-Detect early to treat early. Eur. J. Mol. Clin. Med. 2020;7(5):1206-14.

2. Van der Waal I. Oral potentially malignant disorders: is malignant transformation predictable and preventable? Med Oral Patol Oral Cir Bucal. 2014;19(4):e386.

3. Rathod P, Waingade M, Mahajan M, Jangam DK. Candida in malignant transformation of oral leukoplakia: A. J. Oral Dis. Markers. 2020;3:3-6.

4. Masthan K, Babu NA, Sankari SL, Priyadharsini C. Leukoplakia: A short review on malignant potential. J Pharm Bioallied Sci 2015;7(Suppl 1):S165.

5. Jafarey N, Zaidi S. Carcinoma of the oral cavity and oropharynx in Karachi (Pakistan). An appraisal. Tropical doctor. 1976;6(2):63-7.

6. Izumo T. Oral premalignant lesions: from the pathological viewpoint. International J. Clin. Oncol. 2011;16(1):15-26.

7. Sanfrancesco J, Jones JS, Hansel DE. Diagnostically challenging cases: what are atypia and dysplasia? Urol. Clin. North Am. 2013;40(2):281.

8. Vigneswaran N, El-Naggar AK. Early detection and diagnosis of oral premalignant squamous mucosal lesions. J Biomed Opt : Springer; 2016. p. 601-17.

9. Kabiraj A, Khaitan T, Bhowmick D, Ginjupally U, Bir A, Chatterjee K. Screening of oral potentially malignant disorders using exfoliative cytology: a diagnostic modality. J. Cancer Epidemiol. 2016;2016.
10. Suzuki T, Kikuchi T, Yoshida Y, Sato K, Takano N, Tanaka Y. A study of new cytodiagnosis report format for liquid-based oral cytology in squamous cell carcinoma. Jpn J Oral Diag/Oral Med. 2018;31:187-92.

11. Suzuki T, Tanaka Y, Sato K, Katakura A. Evaluating the Bethesda system for liquid-based oral cytology. Jpn J Oral Diag/Oral Med. 2016;29:28-35.

12. Babshet M, Nandimath $\mathrm{K}$, Pervatikar S, Naikmasur V. Efficacy of oral brush cytology in the evaluation of the oral premalignant and malignant lesions. J Cytol. $2011 ; 28(4): 165$.

13. Abidullah $\mathrm{M}$, Raghunath $\mathrm{V}$, Karpe $\mathrm{T}$, Akifuddin $\mathrm{S}$, Imran $\mathrm{S}$, Dhurjati VNN, et al. Clinicopathologic correlation of white, non scrapable oral mucosal surface lesions: A study of 100 cases. Journal of clinical and diagnostic research: JCDR. 2016;10(2):ZC38.

14. Trakroo A, Sunil M, Trivedi A, Garg R, Kulkarni A, Arora $\mathrm{S}$. Efficacy of oral brush biopsy without computer-assisted analysis in oral premalignant and malignant lesions: a study. Journal of international oral health: $\mathrm{JIOH}$. 2015;7(3):33.

15. Gonzalez Segura I, Secchi D, Carrica A, Barello R, Arbelo D, Burgos A, et al. Exfoliative cytology as a tool for monitoring pre-malignant and malignant lesions based on combined stains and morphometry techniques. J Oral Pathol Med 2015;44(3):178-84.

16. Yardimci G, Kutlubay Z, Engin B, Tuzun Y. Precancerous lesions of oral mucosa. World Journal of Clinical Cases: WJCC. 2014;2(12):866.

17. Nair DR, Pruthy R, Pawar U, Chaturvedi P. Oral cancer: Premalignant conditions and screening-an update. J Cancer Res Ther. 2012;8(6):57.

CONFLICT OF INTEREST: Authors declare no conflict of interest

GRANT SUPPORT AND FINANCIAL DISCLOSURE: NIL

\section{AUTHOR'S CONTRIBUTION}

Following authors have made substantial contributions to the manuscript as under

Waris M: $\quad$ Concept, study design, discussion, manuscript writing, facilitation of the reagent and materials, critical review.

Ahmad S: Facilitation of the reagent and materials, critical review, interpretation.

Khan MM: Analysis, interpretation, manuscript writing, study conduction.

Nasir S: $\quad$ Critical review, study conduction.

Mushtaq Q: Planning, study conduction, critical review.

Taj F: $\quad$ Study conduction, discussion, manuscript writing.

Authors agree to be accountable for all aspects of the work in ensuring that questions related to the accuracy or integrity of any part of the work are appropriately investigated and resolved. 